\title{
Envisioning a Rhizomic Audio-Visual Archiving for the Future ${ }^{1}$
}

Nick Deocampo

What shape will audio-visual (AV) archiving take in the future? Archiving in the past has been known for its vital role in keeping holdings of all sorts and shapes. From books to artefacts, archives keep objects singled out for their uniqueness and authenticity, particularly those like no other because things of similar kind have been lost or destroyed. So much power rested on the archives of yesteryears due to their centralized authority over those who did not have what they guarded as their "properties," stored within their well-protected sanctuaries of records.

The old practice of centralization in archiving-whether exercised by learned institutions, corporate establishments, or agents of the stateresulted to what appears to be a linear direction defining its structure and operations as records-keeper. A central figure with great expertise or authority wields power over what to preserve and what not to, following the dictates of forces outside anyone's control. In the more distant past, the greater public could hardly access what were zealously guarded by authorities manning those archives. Similarly, technology imposed its own way of determining what needed to be preserved. One could also not help but notice that much of the discourses about archiving ran in a steady trajectory from West to East, with values oftentimes not suited to the local needs of those they addressed. Seen this way, dependency has been bred into the value system of archiving practices, giving prominence to those with expertise and authority, resources, and their sanctified geo- 
political location. All these gave importance to an archiving ideal favouring hierarchical, centralized, and well-appointed structures which define much of the archival world we know today.

To the preceding observations may be contrasted an alternate way of looking at archives. This view locates itself opposite the established archive's linear trajectory and favors the multiple lines created by multitudes of individuated depositories that store records, for whatever purpose or need they have. By seeing archiving from the perspective of need-the need of those who, despite lacking massive resources, are compelled to store-the view offered in this essay consists of a new paradigm describing an alternate future for AV archiving.

Discharging multiple and diverse forms of archiving begins with the iteration of need. Why is there a need to archive? Whose task is it to archive? How does one archive? All these questions find their relevance in the articulation of wanting to keep something, either individually or collectively. An archive as we all know is more than just a physical space bounded by walls, guarded by an over-zealous staff, conditioned by humidifiers, and locked up only for specialists to keep and use. One wants to think of an archive as having among its stakeholders end-users such as historians, scholars, researchers, teachers, students, artists, scientists, movie fans, and ordinary lay persons, whose need for data, information, and things are paramount to their tasks and interests. They have a strong stake in the acquisition, storage, and access to information and documents.

Established archives have overly-determined structures dominated by forces that impose strained burden upon them, resulting to stymied responses to calls for access by ordinary folks. This situation makes many archives to adopt authoritarian ways in keeping and managing their holdings, typified by inaccessible technology, affluent economics, complex infrastructure, insensitive politics, on top of the archival illiteracy among the populace they serve and the forbidding climate plaguing many archives in places that have humid weather. Except for those forces beyond their control such as climate, these forces have produced an archiving past that saw many institutions becoming dictated, top-down, by a bureaucratic system. Added to these are Western values providing a singularity of vision that tend to homogenize archives of various orientations, aims and resources, into uniform similarity. What you get is an archival environment catering mainly to specialists. While there is no debate in wanting to acquire and share resources needed in archiving such as technology, must archives see the future in familiar homogeneity, when the realities faced by individual archives are those of dissimilarity, differences, and disjointedness?

By becoming aware of the political economy governing the lives of 
archives, one may want to appreciate the variegated personalities that ordinary archives exude due to their inadequacies and limitations. One also needs to value the unique capacities these archives exert in order to store documents, without lumping them into one homogeneous alliance. It is by considering material differences and disparities-economic as well as political - that the archiving world may be thought to be non-homogeneous and, therefore, multiple. For this reason, we need a new paradigm. Archivesbig or small-have different archival resources and varied needs to fulfil. It is these differences that one has to consider by seeing how individual, unique, archiving initiatives can also be a driving force in planning the archives of tomorrow, and not only by a few institutional archives with their massive power to safeguard collections. There is a need to recognize and respect the basic unit of archiving (in the form of individual or community archives in their immense totality) and the philosophy to guide minute archiving in its widespread practice.

In order to achieve this, the theory of Gilles Deleuze and Felix Guattari (1987) on the rhizome will be looked at to see how their rhizomatic model of growth and organization finds significance in drawing up an archival paradigm that will be useful in conceiving the future of AV archiving. This is significant in the light of a future that is shaped by globalism, digital technology, and populism, to mention a few of the driving forces affecting early $21^{\text {st }}$ century society. It is these present-day life-changing forces that cause archives to de-territorialize and assume, in multiple ways, their immanent behavior to store and safeguard documents.

\section{Introducing the Rhizome}

Two paradigms about plant growth applied to social organization are described in the book, A Thousand Plateaus: Capitalism and Schizophrenia, by the two French philosophers, Deleuze and Guattari (1987). They are the arborescent and the rhizomatic. These models can help conceive ways of how audio-visual archives may be modelled.

Using the arborescent model that talks about the vertically and hierarchically structured growth of trees, one finds a parallel in archiving when used to describe a similarly linear and vertical direction of growth and operation while keeping records. This has made archives to aspire for an apex of goals-whether those ideals are brought about by technology, capital, or expertise. Taking a singular path in reaching those goals forces everyone else below the administrative hierarchy to conform to the shape of a tree-like configuration, no matter if alternate options could be taken. Penalty or abandonment awaits those who do not follow the straight path. 
A rhizomatic paradigm offers an alternate track. Because it challenges or opposes the strict hierarchy of ordering archives, its non-conforming ways are bound to be misunderstood or, for those practising it, will be left to their own resources. A rhizomatic model proposes a horizontal, root-like spread of archives, irrespective of individual shapes and sizes, disdaining the rule of One. It forms a rhizomatic field which Deleuze and Guattari (1987) may likely describe as an assemblage, or that which "establishes connections between certain multiplicities" (p. 23). By themselves, archives are multiplicities by virtue of the magnitude, dimensions, and determinations they manifest to keep their holdings. This is irrespective of the type of materials or contents they contain, or the highflying aims or services they aim to do. None has a more superior status than the other-small archives have equal right to exist as state-owned ones. In safeguarding a country's valued documents, it can be to the best interest of the documents that there not be one towering archive to do the job but a multiplicity of archives to fulfil the task. This also applies to a community of archives in a region. It is in this scenario that the theory of the rhizome can be appreciated best. Viewed rhizomatically, each archive fulfils its immanent role in keeping documents while connecting with others in multiple ways and for varied reasons. Compared to nature, this is similar to what we see in gingers and bamboos, where separate stems grow above ground but, underneath the soil, they are connected in a network of roots and affiliations. Connectivity becomes a common trait, with each nodule becoming self-determining in its individual effort to manage its resources and survive. Each unit develops in self-determining fashion but thrives in a multiple ecology of relations together with those of similar nature and pursuits around it.

In this growth paradigm, individual archives are free to discover and develop their own resources, to fulfill unique potentials for growth and to bring to fruition their self-determined goals while connecting to similarlyoperating archives. (Think of digital archives and how they operate.) In facing the future of AV archiving, adopting a rhizomatic paradigm for growth is a welcome answer to the many problems and the crisis of sustainability faced by the AV archive community saddled with problems of bureaucracy and overbearing power dominance. Traditional archiving thrives on a centralized structure that is fostered mainly by the state's effort to control a nations' memory or by privately-owned ones motivated by capitalist interests. An alternate way paves the path toward popularizing the ancient art of record-keeping to a growing population that is shaped by a global ecology, dominated mostly by an audio-visual culture brought about by digital technology. Whatever motivates them to store is enough reason for them to carry on their archiving activity. 
Let us study in detail some features in the Deleuze/Guattari-inspired concept of the rhizome and see how its practice may provide not an essential model of organization (which is an end to itself, a telos, which is not what Deleuze and Guattari intend the rhizome to be) but, rather, a manner, a process, of organizing archival work for communities like those composing the Southeast Asia Pacific Audio Visual Archives Association (SEAPAVAA). ${ }^{2}$ Thinking of the rhizome as an end-goal dissembles a rhizome's principle of having it rooted in the vitality of desire. This makes perfecting SEAPAVAA as an organization (as if it were the singular dream-institution attending to all archives in the region) the exact antithesis for a rhizomatic understanding of structure and organization. Being rhizomatic means thriving in multiplicities, not installing subjectivities and upholding absolutes. It initiates one into a ceaseless web and spread of desires. This results to the deterritorialization of desiring bodies and structures on which is based their capacity to reproduce. Archives are an example. If the desire of those bodies or structures were to keep storing documents, then for SEAPAVAA to become rhizomatic is for it to acknowledge its nature as an assemblage of like-minded records-keepers (that never ends up as a homogeneous body) and then harness its members' individual capacities to perform their immanent task to store. It needs to avoid developing an essentialized identity as a supreme organization dictating its will to archivists in the region. The effort to attend to the multiplicity of functions of its non-homogeneous members results to a sense of indeterminate form which, having the rhizome as model, the structure it builds will consist of diverse forms, or in the words of Deleuze and Guattari: a "body without organs." SEAPAVAA manifests this diversity of membership-from the personal archives in the Philippines to the community archives in Taiwanbut can the path that it take in facing the future be developed and maintained as rhizomatic?

Many established archives may think of themselves as diverse, considering the outward differences they show as depository institutions. But they merely manifest arborescent pseudomultiplicity. ${ }^{4}$ One should not be misled by the multiple characters they outwardly project which are generated by the arborescent structures of the organizations they represent. They seek to achieve end-purposes via linear trajectories that are clearly in the service of a higher authority-whether the state, capitalist landlord, or any hierarchical supreme power. This is unlike the multiplicity one finds in rhizomatic structures which are an immanent part of their being, where storage follows the natural order of the desiring body. As Deleuze and Guattari (1987) explain: "Multiplicity has neither subject nor object, only determinations, magnitudes, and dimensions that cannot increase in number without the multiplicity changing in nature" (p. 8). 
Visibly, at first glance, many of the traditional archives are far from being "subterranean," as they are obviously in the public eye. Several of them even think of themselves as the "only" holding institutions and must remain as the "authority" in their geographic localities to be relied upon in the business of $\mathrm{AV}$ archiving. Outside these institutional archives and under the shadows of these conspicuously-seen establishments, there is a multitude of other "lesser" archives that actually live subterranean lives and which remain invisible to much of the public. Despite their diminutive size, what they keep and how they store their resources have assured the survival of countless precious documents. In fact, their "smallness" assures their viability to survive, although it may not guarantee their longevity. Who they are, and how they will shape and impact the future ecology of archiving, this is the topic to be discussed after a short discussion on the nature of the rhizome.

In describing the rhizome, what is it that one can learn from Deleuze and Guattari? Here is a quote from the partner Frenchmen on how they see it operate:
A rhizome ceaselessly establishes connections between semiotic chains, organizations of power, and circumstances relative to the arts, sciences, and social struggles. A semiotic chain is like a tuber agglomerating very diverse acts, not only linguistic, but also perceptive, mimetic, gestural, and cognitive. (Deleuze \& Guattari, 1987, p. 7)

Comparing the archive to a rhizome, one learns that one's holding capacity as depository of documents and artefacts can be compared to the tuberous, fleshy bulbs buried underground that are fattened by the nutrients they keep. Forming a semiotic chain with other archives, each of them keeps agglomerated holdings that are different and diverse and yet, collectively, are records that are kept with the possibility of becoming attached (formally or not) with others on the basis of their thematic, material, or utilitarian needs. But while one affirms the seeming wholeness of archive-as-rhizome, one cannot help but see the irony of how rhizomes tend to destroy what they have successfully built in the act of continually fulfilling their mandate to preserve, a future that only they can determine for themselves. This is a hard reality faced by many self-sustaining archives which tend to deteriorate into a pile of collectibles or some other decadent forms as their nature transforms into other types of operations. Others of course become strengthened and develop into self-actualizing ones. In minding how archives can grow in a rhizomatic community, organizations like SEAPAVAA may be able to find it their self-generated task to help sustain the future of its member-archives by addressing strategies to survive the odds they collectively face. 
In applying Deleuze and Guattari to interpret SEAPAVAA, one can look at the organization as rhizomatic in the way it maintains the heterogeneity of its membership (a form of "machinic assemblage") and in the way it respects individual capacities to compose and dismantle and transform their tasks of guarding their records (based on changing technology, regimes of power, or other influential forces).While the organization may be critiqued as manned by a hierarchical leadership (but under whose mandate?), its operational function of allowing members to follow their self-determined goals (not goals demanded by SEAPAVAA), echo how rhizomes yield to its parts in per/forming the body. What is rhizomatic about the organization is how its membership spreads in the Asia Pacific region forming like tubers, under no strict command, allowing new growths and organizations to develop in places where capacities to store documents are immanent and palpable. Its growth respects the appearance of each archive in whichever form it comes, from the established National Film and Sound Archive in Australia to a community archive in the USA to a film archive dedicated to genocide in Cambodia. Immanent to each member is the desire, not so much to become a part of the multiple organization, but to preserve and protect its particular holdings. Members are connected with each other for shared reasons (concern for motion pictures, for example) and purpose (to preserve them). Beyond this, the diversity of audio-visual archives from Manila to Phnom Penh, Jakarta to Bangkok, pertaining not only to staterun organizations but to micro-run depositories-shows the wide range of archival organizations composing the association and the great diversity of fulfilling their tasks. This article is not saying SEAPAVAA is already rhizomatic. But in pointing toward its future, it will help the organization immensely if it were to acknowledge such great diversity of archives among its membership reflective of the equally immense diversity of the region they represent. The challenge is how it could forge rhizomatic ways in fostering the association's capacity to fulfil its variegated archival duties without ending up having to set up a bureaucracy as the desirable end in itself.

SEAPAVAA's current growth tends to suggest a teleological progression toward becoming a regional organization providing leadership and direction to the region's archival film community. This is all fine and good, although, clearly, it follows an arborescent growth. Envisioning a rhizomatic future for the organization, however, SEAPAVAA may be made to become an organization resembling an "assemblage" of archives, where each fulfils its own capacity to grow and network with other archives, sharing their capacities to preserve together, but differently and uniquely, operating in a variety of intensities, and allowing its membership to spread in a line of segmentarities as they pursue individual tasks. In this view of the future, 
SEAPAVAA takes on a paradigmatic composition respectful of individual capacities in preserving whatever audio-visual records its members seek to keep. In this collective sense, SEAPAVAA as an assemblage/organization may be able to provide a heterogeneous archival ecology and practice in Southeast Asia.

Seeing SEAPAVAA from an arborescent view, its tree-like development points toward the need for the organization to fix order, plot points, and create linear direction for its member-organizations to follow in its upward mobility as a regional body. This would mean having the organization (or someone in the organization) to dictate SEAPAVAA's every move toward attaining common goals in archiving. But instead of this, or perhaps what one sees so far, is that, like a rhizome, SEAPAVAA has grown into a network composed of institutional and individual, independent as well as community archives, coming together from different countries with their varied and unique capacities as holding institutions remaining intact. The regional body has little, if at all, overbearing domination cast by one organization over its members. In doing so, the organization may be ahead of its time (but therein lies, too, the challenge of sustaining this state of rhizomatic organization and operation).

This particular case of regional structuration does not, regrettably, identically correspond to how some institutional archives developed in their respective countries. These are largely state-run or private institutions which came about as arborescent systems, defined to have "hierarchical systems with centers of significance and subjectification" (Deleuze \& Guattari, 1987, p. 16). This means that many of these archives developed vertically as to allow them to have "localizable linkages between points and positions" (p. 21). This manifests through hierarchical organizations of manpower-from the archive head to the lowly clerk-illustrating the fixity of structure in institutionalized archives. The work plantilla clearly shows the gridded workflow determining their organizations' operations.

Institutional archives are "centered" systems following fixed patterns in their structure, organization, and function. These arborescent archives may be characterized as those oriented toward reaching an apex or a summit such as the crown of a tree. In the case of a centralized archive, the director or chief executive is head; he rules. In such a team, one always finds someone being higher or lower in position than oneself and this situation determines the kind of work ethic and professional relationship governing one's presence in that structure. In this system, the individual's position pre-exists and an archivist is hired to fill up that already predetermined position, with the channels of transmission in her tasks already pre-established. The archivist, as part of the structured archive, is integrated into it at an allotted place. This 
determines one's significance, one's subjectification, within the particular archive system. Mobility in such a closed organization is controlled.

This case is best illustrated under a government bureaucratic system. Archival positions and functions are created ahead to be filled up by persons. It is lucky if someone with excellent records and qualities provides a perfect fit for the job. But in many occasions positions are filled up with people hardly capable of doing their jobs, hence, Deleuze and Guattari (1987) bemoan that the arborescent system is "not a method for the people" (p. 8). This condition results as a consequence of a mandate from the state, or demanded by corporate interests, to form offices that determine one's position as demanded by the designated task. In it, archives have top-down hierarchy no different from how a tree's growth is patterned from its base forming its roots, developing upward toward its trunk and branches, and then forming its leaves; growing in linear, vertical fashion. As one surveys a country's archiving landscape, this vertical pattern is uncannily replicated. The archive stands above the rest of the country as the unique and specialized agency towering over those whose task also is to gather documents. This structure has become the norm to many archiving cultures and one is inclined to think that this is the only way archives can be managed.

To give an example of how such a hierarchical organization can be damaging, a few examples can be cited. One such case is that of the few extant Cebuano films in the Philippines. ${ }^{5}$ At the time when decaying copies (e.g., Badlis sa Kinabuhi) were proposed to be preserved by the National Commission for Culture and the Arts ${ }^{6}$ state policy dictated (way back in the unenlightened Nineties) that non-Manila produced movies were inferior compared to those made in the country's capital (Manila), hence, they could not be given priority attention. This made those regional films to suffer the consequence of getting by-passed for preservation until they were later forgotten. In the case of the film ephemera and other material artefacts, we know that it takes more than films to define an audio-visual culture. For historians, teachers, scholars, researchers, media people, fans, and the legions who see and value knowledge about past films, non-film documents like books, publications, and contemporaneous documents also need as much preservation. Asking existing archives if non-film documents are a priority in their task, the answer that is many times given is "no." So where does this leave historians and scholars who wish to write about film history or the public who craves for information about their movie era of choice go to research on them? They get to go nowhere. The lack of these non-film deposits contribute to our inability to create an informed and robust film culture. 
Considering how much of contemporary life (not just of archives) has been patterned after an arborescent style, the two radical theorists express dissatisfaction at the prevailing model: "We're tired of trees. We should stop believing in trees, roots, and radicles. They've made us suffer too much. All of arborescent culture is founded on them, from biology to linguistics" (Deleuze \& Guattari, 1987, p. 15). And perhaps-may I hasten to add-to archiving, too. This prevalence stems mainly from any state philosophy that propagates and replicates arborescence in so many aspects of social life. The state, fostering an ideology of paternal leadership, demands from its citizens obedience to its laws. Commanding power over its population, the state assumes the upper hand in a striated social order. Seeing how widespread is the dominance caused by arborescent power over much of human affairs, Deleuze and Guattari remind everyone of something elemental in humans before any state could dictate their behaviour and lifestyle: "Thought is not arborescent, and the brain is not a rooted or ramified matter" (p. 15). The key for a new paradigm to become possible in the future lies in that statement. If thought is not arborescent, then there is hope that one can still re-shape the otherwise straight-jacketed world (particularly archives) by capacitating ourselves to continually fulfil our immanent desires and not to teleologically make up an ideal world. The way brains are structured is not tree-like but nodular. This gives hope that one can find alternative ways of organizing AV archives by following how our brain works.

"Decentered" organizations, such as that suggested above, do not rely on the auspices of a government, central authority, or corporate institution to dictate its archival functions. While it is politically significant to get away from the center because it can empower those who are in the margins, favouring minoritarian forces is not the aim of the rhizome. A rhizome has to remain dynamically in-between-committed to acts of "becoming"so that it can play itself out with what it seeks to do. Its attention can be focused on affects, intensities, and state of affairs until it reaches the plane of consistency that it aspires to achieve. When seen in archiving, the direction one finds is the movement toward "participatory archiving," a kind of democracy, that allows AV archivists to fulfil their role as document preservers.

\section{Mapping the archives}

Deleuze and Guattari draw another parallel to a rhizome that is beneficial to our understanding of the workings of the archive. It is the map. The two believe that the rhizome

...pertains to a map that must be produced, constructed, a map that is always detachable, connectable, reversible, 
modifiable, and has multiple entryways and exits and its own lines of flight. It is tracings that must be put on the map, not the opposite. In contrast to centered (even polycentric) systems with hierarchical modes of communication and pre-established paths, the rhizome is an acentered, nonhierarchical, nonsignifying system without a General and without an organizing memory or central automaton, defined solely by a circulation of states. (Deleuze \& Guattari, 1987, p. 21)

More than comparing an archive to a rootcrop, a comparison to a map has greater relevance to SEAPAVAA. This is because a map can relate more meaningfully to the geographic spread of the countries composing the association, which is by nature archipelagic. As a continent that is composed of a fragmentation of island-countries, the map it produces uncannily resembles a rhizome. Such cartography reveals many rhizomatic traits, showing how this map can be "open and connectible in all of its dimensions" (Deleuze \& Guattari, 1987, p. 12). Composed of varying nations, SEAPAVAA constitutes an archival organization that did not-and does not (or perhaps, not yet)-premeditate on its own composition but only serves as a constituted body of member-archives that conjugate or detach according to the archival desires each member organization adheres to. If it continues to operate as a "map," the association will appear as an "acentered institution," a "body without organs," that metamorphoses according to the needs demanded upon it by its member archives. So long as SEAPAVAA fulfils its immanent capacity to safekeep its resources without resorting to a hierarchical bureaucracy, the path toward attaining a rhizomatic organization remains a possibility.

When that happens SEAPAVAA as a regional organization best serves as a nodal base-what Deleuze and Guattari (1987) call as "middle"-a regional hub that does not take away the individuality of its members and control their personal holdings or actuations; rather it guides its members, mentors them, inspires them, and shares resources and ways with them on how to archive their resources. Like in a rhizome, members are free to enter and exit, follow lines of flight between them, and like nomads, territorialize boundaries that need to be traversed.

In a rhizomatic assemblage, each member-archive is a line of segmented articulation, a "segmentarity" - an archive for this and for that. A movie fan has an archive for her favourite movie stars; a historian archives her library; a cook guards her secret recipes; a government encrypts its documents, and a corporation stores its collected data. With each of these, the archive begins its nomadic journey. It tolls the bell for the singular, all-authoritative 
institutional archive as popular demand to store and share documents and information inundates the virtual world. "There are no points or positions in a rhizome. There are only lines," so declared Deleuze and Guattari (1987, p. 8). Rhizomes allow intermeshing organizations like underground bulbs to proliferate and interact with each other. One sees the same proliferation of archived AV holdings in the internet. There is now a multitude of available records in the information highway buoyed by the very populism supporting digital technology. This has allowed globalization to attain a multiplicity of meanings and functions not accessed by humankind with such magnitude before.

Deleuze and Guattari (1987) may have had, perhaps, conceived a model in the rhizome which, decades ago, unwittingly prophesied the complex multiplicities characterizing the digital world now. As early as the Sixties, the two have seen the beauty and applicability of the rhizome in working out what the wired future would embody. They wrote:

...the rhizome is made only of lines: lines of segmentarity and stratification as its dimensions, and the line of flight or deterritorialization as the maximum dimension after which the multiplicity undergoes metamorphosis, changes in nature. These lines, or lineaments, should not be confused with lineages of the arborescent type, which are merely localizable linkages between points and positions. Unlike the tree, the rhizome is not the object of reproduction: neither external reproduction as image-tree nor internal reproduction as tree-structure. (p. 21)

The way digital technology revolutionized production has provided new ways of distribution and, in the case of archives, ways of keeping commodities in circulation to be stored, whether they come from data carriers (film reels or discs) or as objects themselves (the films themselves or their ephemera like posters or photographs). The growing accessibility offered by the digital medium has turned hoarders of film documents to individual independent repositories in no need of centralized institutions to operate their modest, but no less significant, stockpile of resources. This gave rise to individuated pools of accumulated resources, providing archival holdings of unique audio-visual collections as seen in the members of SEAPAVAA. We see some of the "renegade" storehouses in the association creating their own online archives or uploading their collections in popular internet sharing sites. We see this phenomenon more palpably among archives that fall outside the regional association. In the Philippines, an example is Video 48 which has served as a helpful destination for film afficionados and film scholars alike. 
It is a site where people can rummage through its treasure-trove of data on Philippine cinema. While familiar categories give order to the website's mass of data, users are free to roam it in countless ways. The unfettered entryways provided by the online archive recalls what Deleuze and Guattari call as "map," where one could freely navigate the digital domain.

Let everyone also be reminded that rhizomes are "anti-genealogy." By this, one is challenged to think that archives do not have clear beginnings nor ends. In rhizomatic terms, they are a web of multiplicities. They are capable of changing dimensions, metamorphosing into states that will likely change their nature, i.e. in manners of filing from physical storage to digital safekeeping. We are reminded by Deleuze and Guattari (1987) that a "rhizome operates by variation, expansion, conquest, capture, offshoots" (p. 21). These spell the big difference when compared to traditional archives whose growth is often caught in stasis, blamed on the heavy weight that, say, bureaucracy imposes. But with the digital future in everyone's midst, even traditional AV archives are adapting to forces that drastically transform the world, a world that may be seen to be turning closer to becoming rhizomatic.

Three of the life-changing forces happening in our midst are caused by the following: globalism, digital technology, and populism. How will archives be affected by these overwhelming forces that incessantly impinge on contemporary lifeways? With digital technology, many traditional archives may soon loosen their grip over what have been (mistakenly) construed as their sole archival domain and chore. With the new generation of digitally-savvy users entering the world of archiving, (or comfortably working outside it), their mastery of digital technology will in time overtake traditional methods of archiving. The world where archiving becomes accessible to everyone hews closer to the virtual digital network that one finds in the World Wide Web and whose theoretical paradigm Deleuze and Guattari have philosophically envisioned decades ago. Seeing how digital technology has defined and hastened the shaping of a globalized world, and the speed upon which populism has taken into using digital technology, it is not farfetched when archiving will be caught up in the wave of popular demand by interest groups to take charge of archiving matters, as these affect them personally or their communities.

Interestingly, Deleuze and Guattari (1987) provide us with an operative concept which corresponds to the capacities manifested by organizations like SEAPAVAA. This comes in the form of the concept of "alliance," or better yet, of the earlier mentioned "assemblage." With its interlocking bulbs and tubers, what better way to look at a rhizome but one that is composed as an assemblage-an alliance of bodies similarly composed but differently 
shaped, all belonging to the same plant or body put together by a middle. Giving us something to think about, Deleuze and Guattari have this to say: "A rhizome has no beginning or end; it is always in the middle, between things, interbeing, intermezzo. The tree is filiation, but the rhizome is alliance, uniquely alliance" (p. 25).

In forecasting a rhizomatic future for AV archiving in the region, we need to think of ways that archives can adopt to a changing world and its many intersectionalities-individual, national, regional, and global. Thinking of the region's archives, proposing a rhizomatic AV archiving applies well to the archipelagic geography of the countries belonging to the Asia-Pacific. Our region has differing natural climates and ecologies and varying economic, social and technological growths. Applying a stringent, striated, system to make all archives conform to a teleologically-determined system would only create resentments from those that could not cope with the pressure of becoming part of a homogeneous system. A rhizomatic system, however, could bring about policies in running archives that will be attuned to the real workings of our environment, addressing our diverse cultures and social systems. While all these sound good and appealing, one cannot help but also be wary of the ugly (if not destructive) side of a rhizomatic order, which may bring about the nightmare of seeing archives going each its own way at the expense of others, heightening tribalism, or eliciting reactive and paranoiac tendencies that could only hinder a robust flourishing of a community of archives.

Faced with the geo-physiological differences our living in a territorially fragmented region such as Asia, we need to come to terms with our dissimilarities with Europe and the Americas as among ourselves. Such differences are enough to warrant a change of perspective not only in ecological matters but also in the manner of how things are organized, such as the way our archives are to be operated. If our environmental and material worlds are different, should not our archives be diverse as well? Obviously so. Capitalizing on the apparent physical features of our differences, we can consider climatic and material differences as the first expressions of rhizomatic divergence. Unleashing the powers of the rhizome in other ways may lead us to profit from our immanent and unique qualities, rather than forcing ourselves to conform into homogeneous personalities that we are not.

Faced further by forces driving major changes in the world today, we need to create our own response to digital technology. What is the role that digital technology plays in the acquisition, preservation, and access of records? How does digital technology make it possible for even just one, single, person, or institution, or collective, to become equipped and 
fully functional as to be able to do its own archiving? Without allowing technology to over-determine one's need to archive, one may point out how digital technology, if properly utilized, brings about a brave new world in archiving: how it offers a tool, a technology, to preserve our documents through the power of the computer.

To illustrate, we may look at the documents contained inside our computer Inbox and find personal communications, letters, attached files, library of texts and sounds, even photographs and selfies-all digital records that have been kept, deleted and accessed at any time one had the need to. In keeping one's Inbox or website, one actually practices a basic, simple, form of archiving, with possibilities of stepping it up from a mere personal collection to a more complex archival deposit. Then there are communal storage sites like YouTube, Twitter, Facebook, Vimeo, Cloud, and personal or institutional websites, even apps, that are used to contain useful data. As one adds to and deletes digital records, almost anyone is practising archiving. We only need better archiving literacy to make ourselves aware of what and how archiving can be beneficial to us in safeguarding records.

While personal archive may be part of a global internet infrastructure whose hand in managing our accounts may remain invisible, there is no doubt that (within the bounds of controlling our personal accounts) we have learned to keep our records and retrieve them at any time we need to. Without being fully aware, the digital age has turned all of us into a seano, an ocean - of virtual archivists. In this awesome universe of electronic users, each of us holds our personal, unique documentary holdings. The old archival model managed by a hierarchy of authority may be over, although still a necessity for others who need more time to adapt to the changing world of archiving. What is foreseeable is the huge constellation of archivists mindful and minding their individual online archives, and like a rhizome, connecting and interlinking with each other (as in an "assemblage" or "alliance"), forming a web of linkages that map out the virtual, digital, archival, universe. This appears to be the future that we need to consider: when all of us will have the capacity to become our own archivists.

But while there are positive rewards to have in becoming our own individual or communal archivists, it will be best if we are warned that having control of technology may lead others to exploit and corrupt the process of archiving. This may happen when false data are stored or, worse, spread for others to (mis)use. In such a case, how should one address issues like the authenticity of a document? In the age of fake news and fabricated stories, who determines the authenticity of documents? How sure is an archivist that what she keeps is authentic? With regard to protecting intellectual copyright, ownership will be hard to attribute and get compensated in a 
virtual world where access is hard to monitor, especially considering the harm that hacking can inflict. Admittedly, there are new problems one needs to confront as a new horizon in archiving dawns. It is in situations like these when one sees how the rhizomatic system has yet to develop its own methodology beyond the seductive philosophy it elicits. The idea of a global virtual network of archives indeed has its own utopia that also needs to be constantly critiqued.

It is obvious that there is no guarantee that everything that is kept digitally will be to everyone's best interest. Digital archives are vulnerable to abuse by those who have misguided purposes of fabricating false data and disseminating them to the public. Virtuality, when pushed to the limit, will create a world that will test notions of the "real" and the "true," as presently known and valued. It is to our interest that we become aware of the two-sided edge of digital technology in archiving. This is similar to the call made by Deleuze and Guattari in What is Philosophy? (1991) when the two forewarned that a line of flight can at anytime evolve into a line of destruction (and one may add: virtual fabrication). The social media as it becomes the bearer of much of present-day virtual memory, has also become the site for fake news and damaging information, meant to destroy but also to fabulate a separate "un-reality." What had been trumpeted as the democratizing capacity of technology to keep and circulate humanity's collective memory online can likewise become expropriated for somebody's gain, a case of capitalist aggrandizement or, simply, partisan abuse.

Despite all misgivings that virtual archiving brings, there is no way of going back to the medieval methods of keeping records. Collectively, individual archives in the internet have become the "weeds" virtually flourishing in the internet dwarfed by the totemic poles represented by the national and corporate AV archives still dominating the real world. While traditional root-tree agencies continue to find relevance in our arborescent societies, they run short of addressing a task that is simply huge and daunting. This is when non-establishment archives can become essential in tackling the awesome task. It is in the weed-like repositories where effectual connections are more viably made, as their rhizomatic nature allows them to network with similarly placed sites in a free exchange of resources. While established archives keep standard film collections, the oftentimes nondescript ones keep specialized deposits containing non-commercial films like the discarded Super 8 and analogue videos of obsolete formats as well as filmic ephemera like autographed photos and fan magazines. In their virtual capacities, online sites fulfil their tasks for digital collection, displaying a unique network of archival deposits. 
In the non-virtual world, individual archives are hard-put in dealing with collections that do not align with the mandated repertoire of films to be kept by state-sponsored or commercially-oriented archives. This results to the neglect and eventual loss of films that do not fall under the closed system of collection practised by root-tree archives. Falling victim to this neglect are two collections that demand our attention: "orphan films" and AV "documentary heritage." Both ache for their own archives to serve as assemblages for these neglected ones that are counted among our ever diminishing audio-visual legacy.

\section{Orphan Film and AV Documentary Heritage}

In defining "orphan film," Paolo Cherchi-Usai $(1999,2009)$ mentions four ways a film can be orphaned: legal, authorial, material, and archival. When a film loses legal ownership or authorship, a film is bound to become orphaned. Discarding a film's original material such as the shift from $35 \mathrm{~mm}$ to digital copy also orphans a film, while archives orphan a film by the sheer practical act of not preserving it. In this way, how many orphan films are out there wasting away? Few archives specialize on this urgent need to preserve them, while traditional archives tend to ignore them. This is lamentable in the light of the shift from celluloid to digital. How many of these films became orphaned because they did not fall within the priorities set by an arborescent archival system, whose mandate it is to save only commercial, mainstream, popular films? To give an example of this situation, the Philippines alone can provide numerous cases of film neglect resulting to the phenomenon of orphan films. One case is the country's largest privately-owned ethnographic audio-visual collection by a Filipino dance master, Ramon Obusan. ${ }^{7}$ His films, mostly shot in the now obsolete Super $8 \mathrm{~mm}$ film as well as the equally obsolete betamax and the still surviving VHS formats, are about indigenous dances in the Philippines as well as in Southeast Asia. For years, they have been wasting away in plastic containers, unable to find a home in any of the government archives. Now that the dance master is gone, the collection is thankfully stored in the Cultural Center of the Philippines but, being in Super 8 and documentary, their digital preservation has not been a priority.

Starting in the 1990s, a Filipino national artist, Jose Maceda, had his musical recording instruments preserved but not his audio-visual documentations of Philippine and Southeast Asian indigenous songs. His documentaries were kept in one corner of a university office desperately crying out to be preserved. Later receiving a grant, original documents were digitized, which made the $16 \mathrm{~mm}$ film prints and open-reel sound tape recordings becoming officially orphaned. In the Cultural Center of 
the Philippines hundreds of video cassettes are stacked up against a wall, entries to an amateur video competition. Together with those submitted to the Cinemalaya festival competition, those digital entries deserve preservation, whether they won or lost. As digital productions explode in countless islands, how many of the regional digital works will survive the harsh realities surrounding the life of an abandoned moving picture? The examples mentioned may all come under a rhizomatic structure, where each of these collections-specific and unique-may be in the care of a specialized archive. What needs to be done is to create mechanisms to fund and enable specialized archives using digital technology to supplement what big official archives cannot, or unwilling, to do. With so many films and videos around, it is sad to think that there are so few parents to own what one day will become orphaned digital videos.

Across Asia and the Pacific, similar horror stories can be heard, with hardly any archive caring for orphan films. In Thailand, archivist Dome Sukvong fought major battles to secure films made domestically as well as those produced abroad to be stored in an archive that would adopt an open policy in acquiring and accessing films (Rithdee, 2018). ${ }^{8}$ He even took under his care a few "lost" films from the Philippines that became "orphaned" after their commercial screenings in Laos and Cambodia ended in the fifties, ending up as curiosities because of their alien nationality. Serving as surrogate father to the films, he preserved and made negatives out of them. Through his efforts, sparkling new prints of Filipino popular movies like Darna and Dyesebel-long considered "lost"-were sent back to their country of origin.

In Vietnam, government propaganda films were orphaned by the Vietnam War but now, slowly, they find ways of getting preserved and parented again. In Malaysia, as in many parts of Asia-Pacific, hundreds of amateur movies were produced ever since digital cameras appeared in the market. Who keeps them and looks after their preservation? What can be made out of films across the region that are short, silent, amateur, smallgauge, large-format, documentary, educational, experimental, home movie, outtake, government propaganda, student-made, industrial, advertising, and other non-conforming, non-conventional types? Do these amateur movies stand a chance to survive beyond their initial screenings? Will they become priorities of state-owned archives that have their sights aimed at preserving only commercial, feature-length movies? Without waiting for a state archive or a corporate archive to preserve orphan films, would there be anyone or institution passionate enough to initiate their preservation and make them available to the public? Appeal can be made to the region's archive communities to give attention to small-scale archiving, those 
that can provide first aid to the vastly-damaged films twice orphaned by producers who abandoned them and those archives that do not see them as priority for preservation. What may be modestly proposed is for a new archival paradigm to be set up that will preserve orphan films. This begs for the archiving system to rhizomatically transform and produce nodules specifically attending to this and many other needs.

Another archive that can be advocated for is the one meant for nonfilmic materials comprising of the region's AV documentary heritage. Giving drama to this need is the case of the collection by a die-hard fan, Mandy Diaz, of the Philippines' popular actress, Nora Aunor. His memorabilia was lost in an instant after a big flood inundated his house and washed away all valuable archival materials that took a lifetime to collect. If these nonfilm documents are clearly not in the priority of state-run and corporate archives, then what chances have other ephemeral documents got to survive in the future?

But not all is tragic in the archival world. One best practice in preserving film ephemera in digital format is that done by the already mentioned website, Video 48. It is a vast virtual repository set up by a Filipino cineaste, Simon Santos. ${ }^{9}$ All sorts of digitized clippings, posters, photos, video clips and so many more can be accessed in the site, for free. The web owner is no expert in archiving but he managed to store and made accessible his film holdings to the public. Video 48 is one proof of a small, unassuming, personally-initiated, privately-funded, archive which services scholars, academics, and historians as are ordinary film fans.

\section{Conclusion}

The above discussion all point to one thing: archive follows the direction of public access. This begs for a new paradigm to understand its phenomenon and point it forward. The way an archive will work will no longer be a topdown operation nor a down-up dictate. But it will be one starting from the "middle," a concept imbued with the principles developed throughout this essay-that of the rhizome. Operating from the middle, driven by the impetus of desire, allows for an archive to adopt multiple ways of fulfilling its immanent task to preserve documents.

Drawing up the rhizomatic concept, Deleuze and Guattari (1987) based it on the following principles that need to inform what is suggested in this essay: first and second principles, "connection" and "heterogeneity" as they allow any point of a rhizome to be connected to any other point because a rhizome is composed of dimensions rather than plot points; third, "multiplicity", where every element is complete in and of itself, capable of regenerating and re-growing by expansion, conquest, capture, 
and offshoots; fourth, "asignifying rupture" which makes possible for a rhizome to be cut into several pieces but it always grows again from those cut locations, this way avoiding the separation of structures by starting up again on its old lines, or growing on new lines; fifth and sixth, "cartography" and "decalcomania" as these principles pertain to the construction of a cartographic map that forms connections between the map and the actual terrain, containing multiple entrances and exits as compared to a tracing which merely reproduces the world it imitates.

A rhizomatic archive can be one that signifies freedom from the overbearing conventions practised through centuries and which dominated and continue to do so in the way documents are preserved and stored. It seeks to engage all types of stakeholders: be they in government, private media, academe, business, arts, and all other sectors of the general public life. In this way, existing power structures are challenged with regard to the way they hold many of the archives hostage to politics and capitalism. This challenge can be waged through de-centralizing the archival system, loosening their hegemony over the documents they keep, and making archival services available to the many users in ways that are democratic and more open. Similarly, one can hope that arborescent institutions like state-owned archives develop policies that will make them open to keeping specialized holdings like orphan films and widening their archival mandate to keep ephemeral documents among the many other things stored; in short, intensifying their capacities to safeguard documents. This way, a plane of immanence can be maintained among agencies notoriously known to be arborescent and share their holding capacities with the greater public.

In the future, resources will be dispersed from the few to the many, like what we see in the virtual world of computers. Dispersed archival collections can have objects (otherwise deemed worthless) redeem their sense of belonging and use. Reliance over a central authority becomes challenged as usage of archival documents can be sourced elsewhere. In meeting this challenge, archives have to consciously evolve into polyphonic, polymorphic, polyfunctional organizations that will have to be multi-perspectival in their orientation, multivalent in their values, and multi-purpose in servicing end-users, whose needs are many, dispersed, and different. In anticipating this "new" world, one cannot help but recall Deleuze and Guattari's (1991) concept of fabulation and their way of conjuring a future like that of the archive, and of SEAPAVAA as a particular precursor of an aggrupation of a people yet to come. In practical terms, in an archival world where power is unequal, one can think of a people that will be more literate in their regard of archiving. This could foster a new future where they will live out their desire to store and to keep things in ways that will go beyond mere structuration. 
One also needs to prepare the inevitable destruction of these conventional structures (like the archives) in order to inhabit new-i.e. territorializetransformed bodies which will be the new keepers of records, the new archives. One does not need to only hope but must also learn how to will, invent, educate, the people of the future who will build these new archives.

Casting aside a utopian or idealistic future, one may have to think of keeping the archive as a task that will shared by all, big or small, forming an ecology where nothing is wasted because things are kept in places where they find their use. When that happens the archive as we now know it will become shattered into a thousand pieces, where the renegade is in step with the established in preserving documents, creating a world brought to a level of immanent capacity and the power to store. Both the rhizome and the root-tree should not be seen in never-ending antagonism with each other, resulting to either-or options that could only result into futile inaction. Rather, they are to be seen as a movement that transpires between stability and flow, structure and escape. Even what is called rubbish will find use in someone else's archive.

Looking at how archives are forms of organization whose future needs new perspectives of construction and experimentation, Scott Lawley's (2005) thoughts on the significance of the rhizome in the study of an archive's organization are worth reflecting upon: "It is with a constant movement and interplay between the rhizomatic and arboreal aspects of the concept of the rhizome itself that it will continue to develop as an open and useful concept in the study of organization" (p. 46). In so far as archives are forms of organization, reading the rhizome into the archival future allows us to reflect on their organizational domains of power, control, structure, resistance, etc. Opening up borders where we can, we allow more fronts for a conceptual reflection of a rhizome's use in the organization of the future of archiving.

It is by recalling the rhizome's capacity to evoke a sense of movement and ephemerality that one can think of the future of the archive as open and fluid and warn ourselves against its remaining as a closed organization system. This will imbue the rhizomatic archive with a sense of movement and interplay between its different manifestations as an organization, leaving it as a fluid concept with open possibilities for the future.

The future of a rhizomatic archive rests on one that is free and open. 


\section{References:}

Deleuze, G. \& Guattari, F. (1991). What is philosophy? (H. Tomlinson \& G. Burchell, Trans.). France: Columbia University Press

Lawley, S. (2005). Deleuze's Rhizome and the Study of Organization: Conceptual Movement and an open Future. Tamara: Journal of Critical Postmodern Organization Science 3(4), 36-49.

Rithdee, K. (2018, July 31). Guardian of moving images. Bangkok Post. Retrieved from https://www. bangkokpost.com/lifestyle/film/1512986/guardian-of-moving-images.

Usai, P. C. (1999). Orphans of the storm: Saving orphan films in the digital age. What is an orphan film? Definition, rationale, controversy.Paper delivered at the symposium Orphans of the Storm: Saving Orphan Films in the Digital Age, University of South Carolina. Retrieved from http://www.sc.edu/ filmsymposium/archive/orphans2001/usai.html

Usai, P. C. (2009). Are all (analog) films"orphans"?: A pre-digital appraisal. The Moving Image 9(1), pp. 1-18.

\section{Notes}

${ }^{1}$ This article is based on the author's Keynote Address at the 21st SEAPAVAA Conference delivered last April 5, 2017 in Manila.

${ }^{2}$ SEAPAVAA stands for Southeast Asia-Pacific Audiovisual Archive Association was founded in 1996. It is an association of organizations and individuals involved in, or interested in the development of audiovisual archiving in a particular geographic region-the countries of Southeast Asia (the ten member nations of ASEAN), Australasia (Australia and New Zealand), and the Pacific Islands (Micronesia, Melanesia, Polynesia). It particularly aims to promote audiovisual archiving and to preserve and provide access to the region's rich audiovisual heritage.

${ }^{3}$ This is a term Deleuze and Guattari used to refer to an assemblage or body with no underlying organizational principles, seen as having no organs within it.

4 "Arborescent pseudomultiplicity" refers to multiplicities that are generated by arborescent structures or organizations which foster linear trajectories aimed to achieve end-purposes that are clearly in the service of a higher authority — whether of the state, capitalist system, or commanding personality. Deleuze and Guattari mentioned the term in contrast to his notion of multiplicities as being rhizomatic. (Deleuze and Guattari, 8).

${ }^{5} \mathrm{Cebu}$, a central Philippine island from where Cebuano films were produced, was the only other place in the Philippines where once a robust movie industry thrived in the Fifties.

${ }^{6}$ The National Commission for Culture and the Arts is the Philippines' state-designated cultural management and promotions agency.

${ }^{7}$ Ramon Arevalo Obusan (June 16, 1936 - December 21, 2006) was a renowned Filipino dancer and choreographer. He was known for his work in promoting Philippine traditional dance and cultural work. He is also an acclaimed archivist, researcher and documentary filmmaker. His film collection includes the country's largest ethnographic Super $8 \mathrm{~mm}$ film and video footage of ethnic dances and rituals.

${ }^{8}$ Dome Sukvong pioneered film archiving and preservation in Thailand and was head of the Thai Film Archive until he stepped down from his post in 2018. He fought hard to establish the office of film preservation and archiving in the 1980s (Rithdee, 2018). 
${ }^{9}$ Simon Santos is a video collector who set up a virtual online library and archive on Philippine Cinema founded on May 9, 201. His website <https://video48.blogspot.com > contains countless of digitized copies of movie posters, photographs and memorabilia of Filipino popular movies.

NICK DEOCAMPO is a documentary filmmaker and film historian. He is an associate professor at the University of the Philippines Film Institute. His publications include award-winning books on the history of cinema and on film literacy. He has been a recipient of various international fellowships and grants and has served as a jury member in numerous international film festivals. (corresponding author: nadeocampo@yahoo.com.ph). 
136-196 